\title{
AULAS DE CAMPO E EDUCAÇÃO AMBIENTAL: POTENCIALIDADES FORMATIVAS E CONTRIBUIÇÕES PARA O DESENVOLVIMENTO LOCAL SUSTENTÁVEL
}

Maria Elizangela Ramos Junqueira ${ }^{1}$ Simone Santos de Oliveira ${ }^{2}$

Resumo: Esse trabalho intenciona apresentar as contribuições acadêmicas e sociais da aula de campo como estratégias de discussão e formação do sujeito para uma melhor relação/intervenção com o meio ambiente e, sobretudo, para pensar em ações interventivas respaldadas no desenvolvimento local sustentável. Entre as contribuições atribuídas à prática da realização de aulas de campo, podemos citar a aprendizagem e a formação para a compreensão dos diversos e complexos fatores sobre a realidade que envolvem as questões ambientais, além de elaboração de propostas e modelos de atividades socioeconômicas para a prática do desenvolvimento local sustentável.

Palavras-chave: Educação Ambiental; Meio ambiente; Aula de Campo; Potencialidades Formativas; Desenvolvimento Local Sustentável.

${ }^{1}$ Universidade do Estado da Bahia - UNEB. E-mail: elizangela.junqueira@gmail.com

2 Universidade do Estado da Bahia - UNEB. E-mail: ssoliveira_valentec3@yahoo.com.br 


\section{Iniciando o texto: uma introdução}

O ensino de Educação ambiental nos espaços escolares e não escolares assume o caráter obrigatório a partir de 1999, com a Política Nacional de Educação Ambiental. Entretanto, são muitas as dificuldades docentes no que tange à ampliação da temática de forma a contribuir com a formação de indivíduos críticos, imbuídos de valores éticos em relação à vida e com conhecimentos consolidados que possam ser utilizados na intervenção social, situação essa que se encontra distante das necessidades atuais.

Em meio às dificuldades de identificar modalidades didáticas e estratégias metodológicas para o ensino de Educação Ambiental e Meio Ambiente surge a aula de campo como importante procedimento didático que pode contribuir com uma formação de um sujeito mais crítico e consciente, sobretudo no que se refere às questões que envolvem a educação para o desenvolvimento local sustentável no Nordeste brasileiro.

Esse trabalho intenciona apresentar as contribuições acadêmicas e sociais da aula de campo como estratégias de discussão e formação do sujeito para uma melhor relação/intervenção com o meio ambiente e, sobretudo, para pensar em ações interventivas respaldadas no desenvolvimento local sustentável.

A partir das experiências docentes com a prática de aulas de campo, realizadas com estudantes dos cursos de Licenciaturas em Pedagogia, Geografia e Biologia e bacharelado em Administração, no âmbito da Universidade do Estado da Bahia (UNEB), instituição multicampi no Nordeste do Brasil, são descritas contribuições profissionais, afetivas, sociais e econômicas aliadas à construção de uma educação para o desenvolvimento local sustentável, apesar do planejamento e da execução da aula de campo ainda constituir um desafio como modalidade didática na formação inicial e continuada, mas o certo é que a aula de campo se constitui como uma das práticas mais eficientes e estratégia de intervenção pedagógica e social porque possibilita ao sujeito ter contato com os elementos que compõem o quadro natural ou artificial do espaço geográfico.

\section{Educação Ambiental e meio ambiente}

A Educação Ambiental torna-se componente obrigatório a partir de 1999, com a Politica Nacional de Educação Ambiental, estabelecida com a Lei federal 9.795 de 27 de abril de 1999 que dispõe sobre a Educação Ambiental e institui a Política Nacional de Educação Ambiental, além de dar outras providências. No documento é definida a Educação ambiental (BRASIL, 1999, p. 1) como sendo:

Os processos por meio dos quais as pessoas e a comunidade constroem princípios sociais, instruções, capacidades, propósitos e competências voltadas para a conservação do meio 
ambiente, bens do domínio nacional fundamental à sadia qualidade de vida e sua sustentabilidade.

É com esta legislação que percebemos, de forma objetiva, a discussão das questões ambientais nos espaços escolares e não escolares no Brasil, bem como nos outros níveis de ensino, incluindo a apresentação de princípios e objetivos a serem atingidos com o ensino de tais temáticas.

O marco legal prevê impacto nos currículos já que é demonstrada a relevância de mudanças e adaptações a fim de cumprir o que é estabelecido.

Segundo Krasilchik (1988), os currículos escolares estão submetidos aos fatores sociais que abrangem desde as transformações tecnológicas, modelos de urbanização, industrialização, bem como o mercado de trabalho, que impulsionam a sociedade a produzirem mudanças nos currículos. Essas transformações ocorridas na sociedade proporcionaram a elevação de alguns conteúdos e/ou temas que tradicionalmente estavam inseridos aos conteúdos de disciplinas específicas a assumirem status de componente curricular. Nesse sentido:

A educação ambiental e a Educação para a Saúde são, de forma geral, programas que estudam as relações dos fatores econômicos e sociais e a melhoria da qualidade de vida, e as possíveis consequências do uso indevido do ambiente (KRASILCHIK, 1988, p. 55).

A compreensão de questões que envolvem a temática ambiental é relevante para a formação profissional dos sujeitos neste novo contexto histórico, haja vista que elas surgem como estratégias de enfrentamento para os diversos problemas que envolvem a sociedade contemporânea, pois temáticas sobre Meio Ambiente nunca foram tão debatidas em todo o cenário mundial como nos dias atuais. O mundo começa a voltar seus olhares para as ações humanas na natureza, cujas relações se estabelecem desde os tempos mais remotos.

Cunha e Guerra (2004, p.23), ao discutirem ambiente ou meio ambiente, afirmam que ele "é social e historicamente produzido e sua construção se faz no processo da interação contínua entre a sociedade que está em movimento e um espaço físico particular que se modifica permanentemente". Portanto, o meio ambiente disponibiliza uma gama de elementos que são essenciais para a vida, sendo imprescindíveis para a sobrevivência de todos os seres vivos existentes no planeta que utilizam os mais variados recursos naturais para a manutenção da existência terrestre, pois "o meio ambiente é bem metaindividual, portanto, de cada indivíduo e de toda a comunidade, considerada de forma ampla e complexa, não sendo possível determinar o número de sujeitos que detém a sua titularidade", nos assegura Arruda (2004, p. 25).

revista brasileira educação ambiental 
Assim sendo, o meio ambiente é o bem de todas as formas de vida existente no globo, de todas as espécies sem distinções, importante também para o equilíbrio dos elementos abióticos que dão sustentação a todo um processo que é fundamental para a harmonia e gerência para a constituição da vida.

Quanto aos impactos ambientais que vêm ocorrendo na atualidade, podemos afirmar que eles fazem parte de um processo histórico de mudanças socioeconômicas e culturais, sobretudo associadas às questões de ordem social porque a sociedade se modifica e altera a maneira como concebe a natureza a partir de valores, crenças e ideais (CUNHA; GUERRA, 2008).

Dentre as dificuldades encontradas para a ampliação das discussões ambientais, temos a ausência/poucas práticas educativas que envolvem as questões ambientais, cujas atividades didático-pedagógicas se resumem a poucas ações, reduzindo-se apenas a algumas atividades ligadas ao dia do meio ambiente, dia da árvore, dia da água, dentre outras datas comemorativas, atividades estas que inviabilizam uma formação de indivíduos críticos, imbuídos de valores éticos em relação à vida e com conhecimentos consolidados sobre 0 arcabouço teórico-ideológico-prático no que tange às questões ambientais, de maneira que possam ser utilizados na intervenção social, encontrando-se distante das necessidades atuais que emergem na sociedade, pois é urgente o desenvolvimento da competência política, no que se refere ao sujeito capaz de conduzir sua história, autônomo na conjuntura social, como nos assegura Demo (2002).

$\mathrm{Na}$ trajetória da organização de estratégias capazes de assegurar o desenvolvimento de competências e habilidades para a convivência sustentável com o ambiente, foram elaboradas leis que culminaram na Política Nacional para a Educação Ambiental, sendo esta o resultado de um longo processo de amadurecimento legislativo que se tornou transparente com a elaboração da Lei no 6.398 que dispõe sobre a Política do Meio Ambiente (BRASIL, 1981).

Nessa legislação, no Artigo $2^{\circ}$, da Lei no 6.398 , é previsto como princípio da Política Nacional de Meio Ambiente a "educação ambiental a todos os níveis de ensino, inclusive a educação da comunidade, objetivando capacitá-la para participação ativa na defesa do meio ambiente" (BRASIL, 1981).

Em 1988, com a promulgação da nova Constituição Federal, essas ideias que envolvem as questões ambientais no âmbito educacional são reforçadas através da inscrição do Meio ambiente no Artigo 225 (BRASIL, 1988) desse documento oficial, ao colocar que:

Todos têm direito ao meio ambiente ecologicamente equilibrado, bem de uso comum do povo e essencial à sadia qualidade de vida, impondo-se ao Poder Público e à coletividade o dever de defendê-lo e preservá-lo para as presentes e futuras. 
Ainda no inciso VI, do artigo supracitado, ressalva que "promover a educação ambiental em todos os níveis de ensino e a conscientização pública para a preservação do meio ambiente" (BRASIL, 1988), demonstrando o interesse na disseminação da Educação Ambiental em todos os níveis de ensino no país.

Alinhado aos princípios propostos na Constituição Federal (BRASIL, 1988) e na legislação, o Ministério da Educação publica os Parâmetros Curriculares Nacionais sobre Meio ambiente (BRASIL, 1997a), considerados como mais um documento oficial que fundamenta as práticas educacionais, sobretudo no que concerne aos temas transversais, como o de Meio Ambiente, devendo ser amplamente utilizado nas discussões das mais variadas disciplinas que formam o currículo escolar.

Apesar desses avanços, o desenvolvimento de ações que envolvem a Educação Ambiental e a sua contextualização do ensino é um grande desafio no Semiárido do Brasil, em decorrência da urgência em desconstruir um processo complexo de estigmas e conceitos formados sobre o que seria apropriado para ser objeto de estudo no meio ambiente.

Em meio às dificuldades de identificar modalidades didáticas e estratégias metodológicas para o ensino de Educação ambiental e meio ambiente, surge a aula de campo como dispositivo metodológico/didático relevante para a construção de uma educação significativa, ancorada nas discussões e ações que envolvem o desenvolvimento local sustentável no Nordeste brasileiro.

É importante destacar iniciativas para a construção de modelos locais e didáticos para a Educação Ambiental no Semiárido do Brasil, uma vez que a maioria dos modelos propostos para a Educação Ambiental apresentados nos livros didáticos implantados nas escolas pelo Plano Nacional do Livro Didático PNLD, no final do século $X X$, nas reportagens e nos documentários são de biomas e vegetação que retratam a região Sudeste, ora relacionado à Mata Atlântica, ora à Floresta Amazônica na região Norte do país, desconsiderando as situações e realidades localizadas em outras regiões ou localidades, deixando evidenciado o pensamento de que no Nordeste brasileiro não existem possibilidades de ensino de Educação Ambiental capaz de propor soluções sustentáveis que integrem as pessoas ao ambiente que envolve o Bioma da caatinga. Tal situação implica uma visão estereotipada dos sujeitos que vivem no Semiárido, ao colocá-los como moradores que não possuem autonomia e capacidade de propor alternativas e efetivar ações que possibilitem o desenvolvimento local e condições que assegurem a dignidade humana. Nesse arcabouço filosófico, o desenvolvimento é influenciado apenas pela intervenção governamental ou internacional.

Segundo Contreras (1999), o modelo de desenvolvimento proposto se transformou em forma de empobrecimento e incapacidade de um elevado número de pessoas que aumenta a cada dia em diversos lugares. 
A ideia de subdesenvolvimento e o discurso de desenvolvimento são construções sociais, ou seja, são representações, não refletem um retrato fiel da realidade, de acordo Contreras (1999), uma vez que a construção social do subdesenvolvimento e do discurso do desenvolvimento é histórica e explica os processos e mecanismos de institucionalização, legitimação e dominação, como afirma 0 autor.

Para grande número de pessoas, a Educação ambiental trata fundamentalmente de reciclar o lixo e de semear espécies de árvores nativas da mata ombrófila restringindo o crescimento de atividades que possam contribuir com o desenvolvimento local sustentável para a região do Semiárido.

\section{Aula de campo: contextualizando a metodologia}

Ao longo das nossas experiências docentes temos preferido alguns procedimentos de ensino para além da sala de aula, selecionando metodologias capazes de integrar os conceitos teóricos às vivências dos alunos, de modo a construir um modelo de aprendizagem direcionada para o desenvolvimento local sustentável e encontramos a aula de campo.

Para a seleção de modalidades didáticas para a docência, é imprescindível a avaliação de alguns critérios e variáveis. Sobre este aspecto, Krasilchik (2004, p. 77) afirma que:

A escolha da modalidade didática para o desenvolvimento de uma aula depende dos conteúdos e dos objetivos selecionados, da classe a que se destina, do tempo e dos recursos disponíveis, assim como dos valores e convicções do professor.

Assim, percebemos que a aula de campo reúne uma série de aspectos positivos porque ela é pensada na perspectiva de integrar os conteúdos de uma aula e a realidade vivenciada numa dada localidade.

E, na perspectiva de participação coletiva no processo de aprendizagem e pesquisa de espaços socioambientais, a aula de campo reduz a possibilidade de uma educação baseada meramente na transmissão de conhecimentos, já que ela possibilita, segundo Santos (2001, p. 117), "[...] estimular uma participação ativa, na qual o sujeito não seja apenas a "fonte de informação", mas também agente de interpretação e análise da realidade vivida".

Essas impressões e observações descritas foram coletadas durante 0 decurso do nosso exercício docente numa universidade pública baiana, nos mais variados cursos de graduação, como Pedagogia, Biologia, Geografia, Administração e na especialização em Educação e Meio Ambiente na mesma instituição de ensino superior. 
Dentre os componentes curriculares ministrados que possuíam relações com a educação ambiental e meio ambiente podemos citar: Ecologia de Campo, Sistemática de Vegetais Superiores, Educação Ambiental, Prática de Ensino em Geografia, Gestão ambiental, Ensino de Ciências I, Fundamentos teóricos e Metodológicos do Ensino de Ciências e Fundamentos teóricos e Metodológicos do Ensino de Geografia.

Para a realização das aulas de campo nos componentes curriculares ministrados, selecionamos diferentes regiões do Estado da Bahia com distintas características, nas quais estabelecemos visitas nas cidades de Salvador, Mata de São João e Arembepe (Região Metropolitana de Salvador); Madre de Deus, Cachoeira e São Felix (Recôncavo Baiano), Lençóis, Iraquara, Itaetê, Palmeiras (Chapada Diamantina) e Itacaré (Sul do estado da Bahia).

Vale salientar que do total dessas atividades de campo realizadas, $90 \%$ delas se constituíram como viagens ${ }^{3}$ de estudo interdisciplinar com outros docentes dos cursos ou parceiros com formações distintas entre as quais destacamos biólogos, geógrafos, pedagogos e contadores.

Fazenda (2003, p. 43) afirma que a interdisciplinaridade configura-se como uma necessidade prática, isto é, "[...] uma exigência natural e interna das ciências, no sentido de uma melhor compreensão da realidade que elas nos fazem conhecer". Assim, a interdisciplinaridade acontece no diálogo entre as ciências, na relação de interação entre os diferentes conteúdos e áreas do conhecimento que ao se interagirem produzem outros conhecimentos, logo, integrar conhecimento pressupõe ainda integrar os sujeitos que aprendem, que difundem e transformam esses conhecimentos, buscando articular o vivido e o investigado, seja também para discutir questões ligadas a qualquer área do conhecimento, sobretudo no que concerne aos assuntos que envolvem o meio ambiente e desenvolvimento local sustentável.

Ainda, segundo Fazenda (2008, p. 18), "cada disciplina precisa ser analisada não apenas no lugar que ocupa na grade, mas nos saberes que contemplam nos conceitos enunciados". De fato, a interdisciplinaridade ocorre na interação existente entre duas ou mais ciências/disciplinas. Essa interação pode ir da simples comunicação de ideias à integração mútua dos conceitos, da epistemologia, da metodologia, dos procedimentos e da organização referentes ao ensino, às atividades de extensão e à pesquisa. Logo, trabalhar a interdisciplinaridade num contexto formativo não significa negar as especialidades e objetividade de cada ciência, como a Biologia e a Geografia, por exemplo. A proposta que norteia a interdisciplinaridade respeita o território

\footnotetext{
${ }^{3} \mathrm{O}$ financiamento do transporte das viagens em $50 \%$ por cento foi patrocinado pelos alunos e em outros $50 \%$ das aulas pela instituição, quando o valor foi pago pela universidade logrou-se grande tempo de espera e de articulação para o envolvimento institucional.
}

revista brasileira educação ambiental 
de investigação de cada campo do conhecimento, bem como distingue os pontos que os unem e que os diferenciam. E, é isso que a aula de campo faz!

\section{Aula de campo: contribuição formativa para o docente universitário}

A aula de campo traz contribuições significativas para o professor universitário porque esta atividade pode se caracterizar como interdisciplinar que possibilita a formação do professor pesquisador, como afirma Pontuschka, Paganelli e Cacete (2007, p. 145) ao dizer que:

O professor de uma disciplina específica com uma atitude interdisciplinar abre a possibilidade de ser um professorpesquisador porque deve selecionar os conteúdos, métodos e técnicas trabalhados em sua disciplina e disponibilizá-los para contribuir com um objeto de estudo em interação com os professores das demais disciplinas.

A modalidade didática aula de campo é um exercício docente que inicialmente contribui com o planejamento individual e coletivo, já que sem organização e programação prévia é inviável a execução desta atividade.

Para viabilizar essa metodologia são necessários esforços institucionais para o fortalecimento de parcerias e promoção da interdisciplinaridade, o que incentiva a agregação de diferentes componentes curriculares para o sucesso da atividade, promovendo a articulação e integração de diversas disciplinas e professores, contribuindo, assim, para a promoção de novas experiências e saberes aos docentes porque possibilita aos mesmos um diálogo mais próximo com o corpo docente envolvido.

A conscientização da gestão sobre as contribuições dessa modalidade didática, bem como o convencimento dos alunos sobre a importância de esforços para a concretização da atividade, produz recompensas que justificam 0 investimento acadêmico, pessoal e financeiro das aulas de campo. como:

A aula de campo constitui um grupo de atividades que se enquadram

Uma nova visão [que] está entrando rapidamente no universo da educação, de que os alunos, além do currículo tradicional, devem conhecer e compreender a realidade onde vivem e onde serão chamados a participar como cidadão e profissionais (DOWBOR, 2006, p. 01).

De fato, a aula de campo possibilita ao sujeito aprendente compreender a realidade onde eles vivem, como afirma Dowbor (2006). Assim, torna-se urgente que se reflita sobre quais modalidades didáticas são capazes de integrar 0 conteúdo conceitual e o estímulo de habilidades para interver nos espaços geográficos a fim de possibilitar o desenvolvimento local sustentável a partir de 
ações interventivas que possam gerar menos impactos ao meio ambiente e promover melhoria econômica aos sujeitos que vivem nas regiões do semiárido baiano.

Para Dowbor (2006) a Educação para o desenvolvimento local está relacionada à compreensão e urgência sobre a formação de sujeitos que no futuro possam efetivar intervenções sociais capazes de mudar sua região e produzir ações construtivas.

Durante o nosso percurso docente foram surgindo indícios dos diversos benefícios que a aula de campo produz para a docência universitária e para o desenvolvimento local sustentável. Esses benefícios compreendem desde contribuições didáticas pedagógicas até aperfeiçoamento das relações profissionais e sociais dos atores envolvidos, bem como a aquisição de uma nova perspectiva para a educação e trabalho com implicação econômica através da geração de renda.

Com o crescimento de iniciativas regionais, exige-se que a educação proposta não seja restrita aos conhecimentos gerais, mas que esses conhecimentos possam ser ressignificados para promover alternativas de ações locais, afirma Dowbor (2006).

\section{Aula de campo: tempo e espaço de integração entre os docentes/discentes}

Entre as atividades interdisciplinares propostas para grupo de professores e alunos, é a aula de campo que produz o maior número de laços afetivos entre colegas.

Temos percebido ao longo dos anos que os docentes que, em algum período, realizaram atividade de campo em parceria estabeleceram melhor relações de amizade ou cordialidade, assegurando espaços de trabalhos mais saudáveis e produtivos.

Essas parcerias tendem a se expandir para a proposição de projetos de pesquisa e extensão, bem como para a abertura de diálogo e discussões mais democráticas no espaço universitário.

Segundo Goergen (2010, p.15) "a educação do futuro deve, por conseguinte, capacitar as pessoas para o diálogo". Nessa abordagem feita por este autor, elaborar atividades conjuntas e propor objetivos comuns no desenvolvimento de ações que possam conduzir o sujeito a se apropriar de vivências práticas estimula o diálogo e constrói possibilidade de desenvolvimento local sustentável.

É importante destacar que o estabelecimento de maior diálogo e afetividade é observado também no desenvolvimento de relações cordiais em relação aos docentes e alunos que percebem na convivência próxima decorrida da aula de campo uma possibilidade de desvelar a si e ao outro, atingindo reciprocidade. 
Para os alunos, a saída da sala de aula tradicional é um momento de descoberta, alegrias, prazer e muitas vezes de perplexidade diante de questões reais confrontadas na prática. Infelizmente, o quadro presente é o da escassez de eventos que possibilitem essa experiência na universidade, seja pela ausência de recursos, tempo, ou até mesmo concepção pedagógica do docente sobre a importância do contato com a realidade local.

No quesito aprendizagem é que se obtém a maior vantagem, pois esse tipo de metodologia atinge todos os envolvidos, sendo constatado nas falas dos discentes ou pelo conteúdo expresso nos textos e documentários produzidos a partir da experiência da aula de campo.

O principal resultado observado entre os alunos é a elaboração mental de modelos de desenvolvimento local sustentável, uma vez que ao comparar o local visitado com a região de origem, os discentes vislumbram novas possibilidades, seja pela valorização da sua comunidade local, seja pela extrapolação de modelos que podem ser utilizados para a intervenção social nos seus lugares de origem, de vivência, de moradia.

Os discentes creditam maior confiança nas informações ministradas por componentes que promovem o confronto entre saber e realidade, o que é alcançado durante as atividades de aula de campo promovidas pelas disciplinas. Um exemplo disso é a questão da privatização dos espaços naturais e da real possibilidade de implantação de projetos turísticos em áreas de caatinga que apenas são vislumbrados quando os estudantes se deparam com comunidades onde o turismo é a forma de desenvolvimento local sustentável usado para a sobrevivência da comunidade.

No território do Sisal baiano, especificamente na região do município de Serrinha, a implantação do turismo religioso ou de itinerários que possuem os diversos pontos de exposição do artesanato local já são discutidos entre os discentes como possibilidades de crescimento econômico para a população.

Aliado aos fatores econômicos, uma prática que produz a reflexão das ações cotidianas e de erros passados podem implicar em mudanças sociais capazes de melhorar as condições de vida da comunidade. Esse fato foi demonstrado através da atividade de campo de iniciativa dos alunos que visando levantar informações sobre quais as ações foram desenvolvidas no município de Serrinha a partir do episódio ocorrido em 1997, no qual aconteceu a intoxicação e morte de dezenas de pessoas por metanol na cachaça devido os fabricantes da bebida terem utilizado vasilhames reciclados a fim de reduzir os custos da produção.

Essas reflexões provocam inquietudes nos discentes que se movimentam a fim de encontrar soluções para os dilemas regionais relacionados ao ambiente.

A ideia de desenvolvimento deve abandonar o conceito de crescimento e incluir a apropriação de desenvolvimento humano que significa um processo de transformação social e econômica que tem nos seus princípios e objetivos o bem 
estar das comunidades aliado à ausência de impactos negativos ao ambiente que possam prejudicar a capacidade futura das próximas gerações e garantir a reprodução de alternativas econômicas (CONTRERAS, 1999).

\section{Considerações finais}

A aula de campo é um desafio como modalidade didática tanto pelas despesas que causam, como pelo trabalho no seu planejamento e execução, mas pode ser considerada como uma das práticas educativas mais eficientes, se considerarmos como procedimento que leva os sujeitos à intervenção social.

Os frutos obtidos a partir dessas experiências vivenciadas na UNEB superam o trabalho de planejamento, empenho institucional e esforço em empreender uma parceria interdisciplinar com outros professores.

Entre as contribuições para o processo de aprendizagem está a compreensão da interação de diversos e complexos fatores sobre a realidade e a urgência de adquirir uma postura autônoma sobre os problemas ambientais que demandam maior tempo e dificuldade de ser atingida quando a aula se restringe ao espaço da sala de aula.

A ampliação de sentimentos de cooperação, afetividade e parceria é também considerada como uma das vantagens da aula de campo, pois esta atividade proporciona naturalmente uma convivência mais próxima entre discente-discente, discentes-docente e docente-docente.

A perspectiva de ludicidade também é uma das características da aula de campo, pois os discentes percebem a atividade como um momento único de prazer e proporciona facilidade na aprendizagem dos conceitos e temas propostos pelas disciplinas envolvidas, além de estimular a criatividade na realização das atividades oriundas da modalidade.

E, a maior contribuição atribuída à aula de campo é a possibilidade de elaboração de propostas e modelos de desenvolvimento local sustentável sugeridas pelos estudantes das mais diversificadas áreas de formação, possíveis de serem aplicadas com certa viabilidade nos seus espaços de ocupação.

Entre outras contribuições atribuídas à prática da realização de aulas de campo, podemos citar a aprendizagem e a formação para a compreensão dos diversos e complexos fatores sobre a realidade que envolve as questões ambientais, além de elaboração de propostas e modelos de atividades socioeconômicas para a prática do desenvolvimento local sustentável que possam ser aplicados com certa viabilidade nos espaços/lugares onde os graduandos vivem, além da possibilidade de descoberta de aptidões locais e alternativas econômicas para a sobrevivência de comunidades sertanejas.

Assim, reafirmamos que a aula de campo contribui significativamente para a formação de sujeitos de intervenção social e de transformações que ampliam 
as potencialidades locais e a conquista de competências políticas, consideradas como elemento fundante para a autonomia dos sujeitos e para a vida social.

\section{REFERÊNCIAS}

ARRUDA, P.T.M. Responsabilização civil decorrente da poluição por resíduos sólidos domésticos. São Paulo: Método, 2004.

BRASIL. Constituição da República Federativa do Brasil. Brasília. Distrito Federal: Senado Federal. 1988. Disponível em: http://www.planalto.gov.br/ccivil 03/constituicao/Constituicao.htm. Acesso em: 19 mar. 2013.

BRASIL. Lei federal 9.795 de 27de abril de 1999. Dispõe sobre a educação ambiental, institui a Política Nacional de Educação Ambiental e dá outras providências. Brasília. Distrito Federal. 27 de abril de 1999. Disponível em: http://www.planalto.gov.br/ccivil 03/Leis/L9795.htm. Acesso em: 10 abr. 2013.

BRASIL. Lei 6.938 de 31 de agosto de 1981 que dispõe sobre a Política Nacional de Meio ambiente, seus fins e mecanismos de formulação e aplicação, e dá outras providências. Diário oficial da União, Poder executivo, Brasília, DF. 2 de setembro de 1981. Disponível em: http://www.planalto.gov.br/ccivil/Leis/L6938org.htm. Acesso. 22 mar. 2013.

BRASIL. Parâmetros Curriculares Nacionais: meio ambiente/ saúde. Secretaria de Educação Fundamental. Brasília: MEC/SEF, 1997a.

BRASIL. Parâmetros Curriculares Nacionais: Ciências Naturais. Secretaria de Educação Fundamental. Brasília: MEC/SEF, 1997.

CONTRERAS, J.P. La construcción social del subdesarrolo y el discurso del desarrollo. In: BRETÓN, V.; GARCÍA, F.; ROCA, A. (Orgs.). Los limites del desarrollo: modelos, 'rotos' y modelos 'por construir' em América Latina y África. Barcelona: Içaria. 1999, p. 25-57.

CUNHA, S.B.; GUERRA, A.J.T. (Org). Impactos ambientais urbanos no Brasil. 2. ed. Rio de Janeiro: Bertrand Brasil, 2004.

CUNHA, S.B.; GUERRA, A.J.T. A questão ambiental: diferentes abordagens. 4. ed. Rio de Janeiro: Bertrand Brasil, 2008.

DEMO, P. A educação pelo avesso: assistência como direito e como problema. 2. ed. São Paulo: Cortez, 2002.

DOWBOR, L. Educação e desenvolvimento local. 2006. Disponível em: http://www.apodesc.org./sites/documentos estudos/ arquivos/desenvolvimentoEDUCACAO E DESENVOLVIMENTO LOCAL Ladislau\%20Dowbor.pdf. Acesso em: 23 mar. 2011.

FAZENDA, I.C.A. Interdisciplinaridade: qual o sentido? São Paulo: Paulus, 2003. 
FAZENDA, I.C.A. O que é interdisciplinaridade? São Paulo: Cortez, 2008.

GOERGEN, P. (Org.) Educação e Diálogo. Maringá: Eduem, 2010.

KRASILCHIK, M. Ensino de Ciências e a formação do cidadão. Em Aberto, Brasília, ano 7, n. 40, out./dez, pp. 55-60, 1988.

KRASILCHIK, M. Prática de ensino de Biologia. 4. ed. São Paulo: Editora da Universidade de São Paulo, 2004.

PONTUSCHKA, N.N., PAGANELLI, T.I.; CACETE, N.H. Para ensinar e aprender a Geografia. São Paulo: Cortez, 2007.

SANTOS, A.D. Metodologias participativas: caminhos para o fortalecimento de espaços públicos socioambientais. São Paulo: Peirópolis, 2001. 